\title{
Interconnection of influent channel and pumping station units
}

\author{
Oleg Glovatskiy", Temur Djavburiyev, Ziyoda Urazmukhamedova, A. Gazaryan and \\ Farkhod Akhmadov \\ Tashkent Institute of Irrigation and Agricultural Mechanization Engineers, Waterpower exploitation \\ and pumping stations, 100000, Tashkent, Kara-Niyaziy str.
}

\begin{abstract}
This paper reports on the results obtained the priority recommended strategy for carrying out reconstructive work aimed of the reliability control and safety of Jizzakh main pumping station. It has been established that the safe operation level of Jizzakh main pumping station is supported under the following conditions: The watermark in the pump station forebay are not lower than 314.55 and watermark in the headpond is not higher than 337.80 and not lower than 336.90 for the main units. At the station, no more than 5 "main" and 2 "subsidiary" units work, one "main" unit must be constantly in reserve.
\end{abstract}

\section{Introduction}

During the methods development for establishing calm and uniform movement of water flow along the canals, the question of interconnections improving of hydraulic mode of influent channel of pumping station, from forebay and water receiver to pump should be considered, which supports guaranteed water return to consumers. The operation mode of Jizzakh main pumping station was analysed on interconnection with the hydraulic mode of influent channel for implementation assigned task.

The problem of development the movement of water in the canal-pumping station system with the aim of improving their interconnections to provide guaranteed water feed, reduces unproductive water and energy resource losses in pump irrigation system.

\section{Method}

Based on the mathematical models, systems of automatic control of water levels in channel and their parameters as is also support of specified operating modes maintenance of approach channels and the pumping station can be developed.

The operation of a large pumping station, such as Jizzakh main pumping station, has such problems that cannot be solved without experimental studies. This particularly regards to power supply facilities of a multi-unit pumping station [1]. The necessity of reconstruct the

\footnotetext{
* Corresponding author: sanat.kx@mail.ru
} 
Jizzakh main pumping station was confirmed during a survey with authors participation in 2016-2018.

\section{Results and discussion}

Water intake in approach channel of Jizzakh main pumping station is performed from the upper pool of control structure on 400 (Yujuralzoloto Group of Companies), so that almost normal water level at mark 314.63 should be maintained in pump station. In fact, the project horizon in the water intake site is not provided. Over the past three years, the water level marks of Jizzakh main pumping station fluctuated within $313.65 \ldots 312.75$, i.e. were on $0.98 \ldots 1.88 \mathrm{~m}$ which means lower than the design minimum water level of downstream is about 312.75 .

Table 1. The values of channel upstream of control structure for various modes.

\begin{tabular}{|c|c|c|}
\hline No. & Approach channel & \\
\hline 1. & Maximum & 314,68 \\
\hline 2. & Normal & 314,63 \\
\hline 3. & Minimum & \\
\hline & a) $1600 \mathrm{~B}-10 / 40$ & 309,90 \\
\hline & b) $2400 \mathrm{~B}-25 / 40$ & 314,55 \\
\hline
\end{tabular}

Safe level operation of Jizzakh main pumping station are provided in the followings:

1. The marks of water levels in forebay pumping station are not lower than 314.55 for the main units.

2. Water level mark in the pressure pool is not higher than 337.80 and not lower than 336.90.

3. The equipment of the pumping station operates in the modes recommended by technical specifications of manufacturers. The cavitation and vibration state of the pump is determined by the characteristic noise and vibration of nodes only.

Measurement of flow total pressure in outlet of suction pipe and comparing them with the initial water levels allows to conclude that the hydraulic losses are insignificant at different flow angles from the receiver $\alpha$ to pump impeller (Table 2).

Table 2. Resistance coefficients at different angles of entry into the intake device

\begin{tabular}{|l|l|l|l|l|}
\hline$\alpha$, degree. & $\Delta \mathrm{H}_{\mathrm{в} m}, \mathrm{~m}$ & $\Delta \mathrm{H}_{c}, \mathrm{~m}$ & $h_{\mathrm{Bm}}$ & $h_{c}$ \\
\hline 0 & 0,0034 & 0,414 & 0,0042 & 0,40 \\
\hline+45 & 0,004 & 0,436 & 0,005 & 0,426 \\
\hline-45 & 0,008 & 0,434 & 0,01 & 0,424 \\
\hline+90 & 0,0048 & 0,396 & 0,00758 & 0,375 \\
\hline-90 & 0,006 & 0395 & 0,0075 & 0375 \\
\hline
\end{tabular}


In the table $\Delta \mathrm{H}_{\mathrm{B} m}, \Delta \mathrm{H}_{c}$ the difference of total pressure input water intake contain structure and in the output section of the suction-pipe.

The resistance coefficient is calculated by the formula

$$
h_{\mathrm{sm}}=\frac{\Delta \mathrm{H}_{\mathrm{B} m}}{\vartheta_{\mathrm{av}}^{2} / 2 g},
$$

Where $\vartheta_{a v}$ - average flow rate in the outlet section of suction-pipe.

On the basis of construction norms and rules, the cascade of pumping station has a damless type of intake structure, where water levels in a river determine water levels in the channel.

Consider the joint operation of approach channel and the pumping station -1 under the following conditions:

a) channel geometry corresponds to design data;

b) actual channel geometry;

c) channel geometry after reconstruction in 1975 and 2006;

d) the cavitation qualities of pumps correspond to their characteristics and determine the maximum possible supply of pumping station -1 for the horizon in Amudarya at the intake point (Cape Pulizindan) $95 \%$ of supply, i.e. $43.4 \mathrm{~m}$ in conditional marks [2].

The approach channel is made in the earthen channel has (according to the project) a trapezoidal section with width at the bottom $35 \mathrm{~m}$, ratio of slopes is 4 , the length is $20 \mathrm{~km}$ and bottom slope is 0.0004 .

Indicate a minimal allowed water level of downstream of the pumping station -1 with $\nabla_{\text {min }}$ channel upstream of control structure. If the mark in Amudarya at the zero picket of channel $\nabla$ efficiency, the difference $\nabla$ efficiency $-\nabla$ downstream $_{\min }=\Delta h_{\max }$ gives the maximum value of delivery pressure for passage friction forces throughout the channel. Recent calculations with a fixed channel geometry and roughness are only a function of flow rate, i.e. $\nabla h=f(Q)$, hence, for the boundary conditions $\nabla$ efficiency - const,$\nabla_{\text {min }}$ channel upstream of control structure - const, largeness $\Delta h_{\max }$ uniquely determines the maximum bandwidth of approach channel, above pumping station -1 cannot supply water.

Table 3. Operation modes of pumping station

\begin{tabular}{|c|c|c|c|c|c|c|}
\hline Number of working units & $\mathbf{1}$ & $\mathbf{2}$ & $\mathbf{3}$ & $\mathbf{4}$ & $\mathbf{5}$ & $\mathbf{6}$ \\
\hline Estimated feed, $\mathrm{m}^{3} / \mathrm{s}$ & 40 & 80 & 120 & 160 & 200 & 240 \\
\hline $\begin{array}{c}\text { Permissible level in the pumping station forebay }-1, \\
\text { according to the pump cavitation requirements, } \mathrm{m}\end{array}$ & 4,8 & 4,6 & 4,5 & 4,5 & 4,6 & 4,7 \\
\hline $\begin{array}{c}\text { The actual minimum levels in the pumping station } \\
\text { forebay -1 are maintained with a shortage of water } \\
\text { level in Amudarya, } m\end{array}$ & 4,0 & 4,2 & 4,4 & 4,7 & 5,0 & 5,8 \\
\hline
\end{tabular}


Levels in pumping station forebay -1 , recommended by the maintenance service, $\mathrm{m}$
4,3

4,48

5,3

\begin{tabular}{|l|l|l|}
5,6 & 5,78 & 6,48 \\
\hline
\end{tabular}

With the operation of the first and second units, the actual depth values are significantly less, pumps operate in the range of cavitation reserves of $20-25 \%$, which provide the area territory. There is an increase in the level of vibration of aggregates, due to unfavorable hydraulic operating conditions. Units Normal operation of is achieved by an additional increase on horizontal water level in the forebay (manual valve deepening).

Engineering survey of pumping station, conducted by the employees of Pumping station laboratory in May 2017, showed that the level in the pump station forebay -1, ensuring the non-cavitation operation of pumps, should be at least 5.5-6.0 $\mathrm{m}$.

Based on the field measurement data, it is necessary to investigate the flow kinematic parameters in the area under study. Usually, the kinematic parameters in hydraulics and hydrology are considered as dimensionless ratios between different characteristic velocities in the flow living section. In fact, that kinematic parameters are used in river hydraulics when solving many practical problems. In this case, knowledge of kinematic parameters at the approaching site allows, to clarify the patterns of flow spreading and its effect on the erosion of the bottom and banks of the channel (Fig. 1).

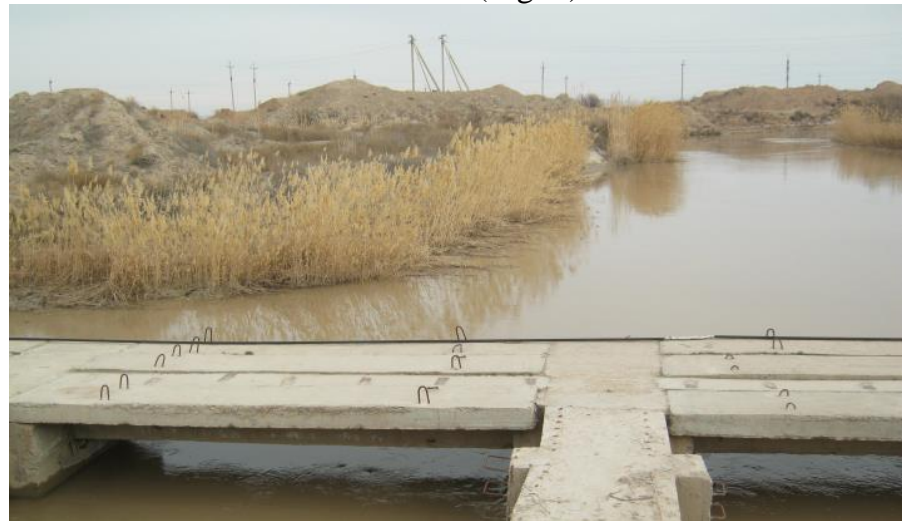

Fig. 1. Approach channel before pumping station

The management of irrigation canals under the conditions of changing water supply to pumping stations requires the use of modern automatic control systems, which allows, in combination with telemechanics and computing equipment, to get the optimal operating conditions of canal sections, hydraulic structures, pumping station and significantly reduce water losses.

In the system of automatic regulation of downstream water level of the pumping station, feedback is carried out by measuring water level of the blocking structure. The measured signal enters into the comparator, where the deviations of the set value of water level with the measured value are determined. Next, the deviation signal enters into water level regulator, where, according to the selected control law, the regulator generates a control action for opening or closing the closure of the partitioning structure.

Consider the description of presented system for regulating downstream water level of the structures on the canal sections.

Channel section -1 :

Boundary conditions at $\mathrm{x}=0$ of the area -1 :

$$
Q_{1}(0, t)=F_{0}(t)=\mu_{0} \omega_{0}(t) \sqrt{2 g\left[z_{\hat{a} \hat{a}}(t)-z_{1}(0, t)\right]},
$$


Regulator equation of downstream water level $\mathrm{P}_{0}$ :

$$
\omega_{0}(t)=W_{r 0}\left(t, H_{0}\left(b_{0}, t\right), H_{0}^{*}(t)\right)
$$

where

$\mathrm{W}_{\mathrm{r} 0}-$ operator of regulator (law) 1 ;

$\mathrm{H}_{0}\left(\mathrm{~b}_{0}, \mathrm{t}\right)$ - water level at the area-1, where located water level indicator;

$\mathrm{b}_{0}$ - distance from area beginning;

$\mathrm{H}^{1} *(\mathrm{t})$ - task to the regulator $\mathrm{P}_{0}$.

Boundary conditions at $\mathrm{x}=11$ area -1 :

$$
\begin{aligned}
& Q_{1}\left(l_{1}, t\right)=F_{1}(t)+Q_{2}(t)+Q_{3}(t), \\
& F_{1}(t)=\mu_{1} \omega_{1}(t) \sqrt{2 g\left[z_{1}\left(l_{1}, t\right)-z_{2}(0, t)\right],}
\end{aligned}
$$

Regulator equation $\mathrm{P}_{1}, \mathrm{P}_{2}$ and $\mathrm{P}_{3}$, downstream water level:

$$
\omega_{2}(t)=W_{r 2}\left(H_{2}\left(b_{2}, t\right), H_{2}^{*}(t)\right),
$$

where

$$
\begin{aligned}
& \mathrm{W}_{\mathrm{r} 0}-\text { operator of regulator (law) } 1 \text {; } \\
& \mathrm{H}_{1}\left(\mathrm{~b}_{1} \mathrm{t}\right) \text { - water mark on the site }-1 \text {, where located water level indicator; } \\
& \mathrm{b}_{1}-\text { distance from area beginning; } \\
& \mathrm{zi}(\mathrm{t}) \text { - task to the regulator } \mathrm{P}_{0} \text {. }
\end{aligned}
$$

The system of regulation of water level of lower downstream works as follows; If, for some reason, the downstream water level increases in comparison with the specified value of water level, then the regulator generates a signal to open the shutter by a certain amount, calculated by the law of regulating. After the shutter is opened, the downstream water blocking structure begins to decrease, since water flow through the blocking structure will be greater than its previous value. The regulator will adjust the opening value the shutter of partitioning structure until water level of lower downstream becomes close to specified value.

In the downstream water level control system in side outlets, water flow control is implemented by adjusting water level in gauging stations located below the outlet that have unique consumption characteristics.

In systems of automatic regulation of water level in the channel sections, various water level regulators are usually used.

In the practice of automating water management systems, hydraulic, electrical and electronic water level regulators are used. Hydraulic regulators generally have continuous regulation laws, while electric and electronic regulators have a discrete action.

The laws of hydraulic regulators depend mainly on their structural elements; in most cases these laws are proportional or proportional-integral $[3,4]$. Electric regulators mainly implement proportional-integro-differential control laws. The use of programmable logic controllers in the system contour of water regulation facilities allows the use of rather complex control laws in the control loop.

Experimental research has shown that in some hydrotechnical and in the power supply facilities of pumping station as a result of planned or bottom narrowing of the channels, free flow surfaces are established, drastically changing the depths and velocities along the stream on a fairly short distance and eventually increasing resistance forces to movement. In addition to resistances caused by the difference in pressure and friction, in accordance 
with the principles of hydromechanics, it is recommended to take into account the vortex formation and inertia forces [3].

\section{Conclusion}

- Regulation of machine water unit operating modes, where the main structures are included: water intake (water receiving) construction, septic tanks (main and for technical water supply), water supply system (channel, gravity pipelines), forebay, water receiver, are one of the main tasks of the pumping station operation.

- It is necessary to ensure the maintenance of optimum water level marks of Jizzakh main pumping station at control structure on 400 (Yujuralzoloto Group of Companies) and the design point of water intake with the implementation of combined structures, reconstruction of water intake. The level in the forebay of the pump station -1 , which provides for non-cavitation operation of pumps, must be at least 5.5-6.0 m.

- Hydraulic regulators that have continuous control laws can be used as programmable logic controllers in the control loop of a water management system.

\section{References}

1. Bazarov D.R., Karimov R.M., Hidirov S.Q., Matyakubov B.SH. Hydraulics II special course, TIIAME, pp 555

2. Zuykov A.L. Hydraulics Vol. 2 M., Ed. MGSU pp.423, (2016)

3. Zuykov A.L. Hydraulics Vol. 1 M., Ed. MGSU pp.456, (2016)

4. Bazarov D.R. and oths. №17/2017 «Development of recommendations for the prevention of channel deformations in the downstream pools of reservoirs» Ministry of Agriculture and Water Management of the Republic of Uzbekistan, pp 80, (Tashkent 2017)

5. Barishnikov N.B., Isaev D. Channel processes. St. Petersburg. Ed. Russian State Hydrometeorological University, pp. 459, (2014)

6. Bazarov D.R., Arafjanov and oths. Channel process, TIIAME, pp 641, (Tashkent 2018)

7. Bazarov D.R. and oth. Mathematical modeling of the operating mode of the AmuBukhara machine channel. International Academy Journal Web of Scholar 1 (19), Vol.1, Website: https://ws-conference.com/ pp. 26-32, (Warsaw, Poland, 00-773, January 2018)

8. Bazarov D.R. and oths. Hydraulic aspects of computer modeling of dramatically changing water flow on pressure hydraulic structures, Irrigation, land reclamation journals Vol. 2 (4), pp. 42-46 (Tashkent 2016)

9. Bazarov D.R. Militeev A.N. Mathematical model for calculating two-dimensional (in plan) deformations of the channels Messages in applied mathematics, Moscow, Ed. Dorodnitsyn Computing Center, (1997)

10. Bazarov D.R., Militeev A.N. Three-dimensional mathematical model of the movement of sediment in the alluvial channels. Messages on applied mathematics, Moscow, Ed. Dorodnitsyn Computing Center, (1997)

11. Rakhimov Sh.Kh., Begimov I., Gafforov Kh.Sh. Necessary conditions for the optimal distribution of water in the canals of irrigation systems under the conditions of 
discreteness of water supply Vol. I // Problems of computer science and energy. №3-4, pp. 48-55, (Tashkent, 2014)

12. Rakhimov Sh.Kh., Gafarov Kh.Sh., Seytov A.J. Mathematical models of irrigation canals taking into account water supply discreteness //Second International Scientific and Practical Conference pp. 239-245, (2016)

13. Glovatskiy O.Y., Nasirova N.R., Artikbekova F.K. Some aspects of the use of pumping stations in the development of water resources in Central Asia in the 21st century // Collection of reports of the 20th International Scientific and Practical Conference "The Northern Sea Route, water and land transport corridors as the basis for the development of Siberia and the Arctic in the 21st century". Vol. I. pp.69-74 (Tyumen: TIU, 2018)

14. Chumachenko B.N. Theoretical foundations and experimental studies with the aim of creating flow-through parts of vane pumps that provide a combination of high efficiency, suction capacity and low vybrat: Avtoref. M.: All-Union Scientific Research Design and Technological Institute of Hydraulic Engineering, pp. 35 (2002).

15. Bazarov D.R. Khalmatov V.A., Toshmatov Kh.K. Reliability of pumping stations // Investigation of the hydraulic regime of the river or dam water intake, reporter of Tashkent State Technical University, № 4 pp. 34-38, (Tashkent 2008)

16. Bazarov D.R., Norkulov B.E., Ruzimetova D.M. Changes in the hydrological regime of the river at the dam intake, Architecture, construction, design Vol. 4, Ed. Tashkent Architectural-building Institute, pp. 39-42 (Tashkent, 2011)

17. Bazarov D.R., Ismagilov Kh. A. Investigation of the hydraulic regime of the river or dam intake, Scientific journal Agriculture of Uzbekistan Vol. 6, pp. 37-38, (1999)

18. Agroskin I.I., Dmitriev G.T., Pukalov F.I. Hydraulics - M.: pp. 352 (Gosenergoizdat, 1964)

19. Shternlikht D.V. Hydraulics - M.: Vol. I, II, III, IV, (Gosenergoizdat, 1991)

20. Rustamov Sh.R. Glovatskiy O.Y. Jankabilov S.U. Gadaev S.K. New designs and technologies for water and energy saving in systems of machine water lifting // Problems of energy and resource saving. Vol. 3-4, T., pp.143-148, (2017)

21. Rustamov Sh. R., Nasirova N. R. Constructive peculiarities of modernized centrifugal pump // European science review, № 3-4. pp. 278-280 (Vienna 2018) 